Geopolítica(s) Revista de estudios sobre espacio y poder ISSN: 2172-3958

https://dx.doi.org/10.5209/geop.69202

\title{
Pandemia: anexiones territoriales en Israel y comorbilidad en Palestina $^{1}$
}

\author{
Isaías Barreñada Bajo²
}

Recibido: 4 de mayo de 2020 / Aceptado: 10 de mayo de 2020

Resumen. La pandemia de 2020 ha vuelto a poner de relieve una serie de aspectos medulares del conflicto israelo-palestino. En Israel ha servido de pretexto para que se conformara un gobierno de unidad nacional capaz de hacer frente a la emergencia sanitaria. Sin embargo el acuerdo ha vuelto a excluir a la minoría palestina y abre la posibilidad de una nueva fase de anexiones territoriales en Cisjordania. En los territorios palestinos la emergencia se suma a la fragilidad estructural que supone la ocupación prolongada y la ausencia de un Estado palestino efectivo y soberano.

Palabras clave: pandemia de COVID-19; Israel; Palestina; anexión territorial; emergencia sanitaria.

\section{[en] Pandemic: Territorial Annexations in Israel and Comorbidity in Palestine}

\begin{abstract}
The 2020 pandemic has once again highlighted a number of core aspects of the IsraeliPalestinian conflict. In Israel, it has served as a pretext for the formation of a national unity government capable of dealing with the health emergency. However, the agreement has again excluded the Palestinian minority and opens the possibility of a new phase of territorial annexations in the West Bank. In the Palestinian territories, the emergency adds to the structural fragility of prolonged occupation and the absence of an effective and sovereign Palestinian State.
\end{abstract}

Keywords: COVID-19 pandemic; Israel; Palestine; territorial annexation; sanitary emergency.

\section{[pt] Pandemia: anexação territorial em Israel e comorbidade na Palestina}

Resumo. A pandemia de 2020 recolocou vários aspetos centrais do conflito israelo-palestino. Em Israel, serviu de pretexto para a formação de um governo de unidade nacional capaz de lidar com a emergência sanitária. No entanto, o acordo excluiu novamente a minoria palestina e abre a possibilidade de uma nova fase de anexações territoriais na Cisjordânia. Nos territórios palestinos, a emergên-

1 La parte de este artículo referida al impacto de la pandemia en la Palestina fue publicada en formato electrónico el 21 de abril de 2020 con el título "Palestina y la pandemia. La ocupación como comorbilidad política", en la serie ICEI papers Covid-19, nº18, [https://www.ucm.es/icei/file/iceipapercovid18].

2 Profesor de Relaciones Internacionales en la Universidad Complutense de Madrid. Investigador del Instituto Complutense de Estudios Internacionales (ICEI).

E-mail: i.barrenada@cps.ucm.es 
cia aumenta a fragilidade estrutural da ocupação prolongada e a ausência de um Estado palestino efetivo e soberano.

Palavras-chave: pandemia da COVID-19; Israel; Palestina; anexação territorio; emergência sanitária.

Sumario. Introducción. 1. La pandemia en Israel, pretexto para excluir. 2. La pandemia en Israel, pretexto para anexar. 3. La pandemia en Palestina, añadida a la ocupación. Reflexiones finales. Referencias.

Cómo citar: Barreñada Bajo, I. (2020). Pandemia: anexiones territoriales en Israel y comorbilidad en Palestina. Geopolitica(s). Revista de estudios sobre espacio y poder, 11(Especial), 93-104.

\section{Introducción}

La propagación de la COVID-19 y su consideración de pandemia global por parte de la OMS el 11 de marzo de 2020 ha dado pie a numerosos análisis desde todas las disciplinas, aplicados a las más diversas situaciones existentes. Entre otros ha llamado particularmente la atención cómo esta crisis global y multidimensional impacta en situaciones excepcionales y extremas, como países con Estados extremadamente frágiles o fallidos, en los conflictos armados, y cómo afecta a la población refugiada, desplazada o migrante precaria. Un escenario de contagio masivo en tales situaciones podría acarrear una catástrofe añadida, colapsando las ya de por sí limitadas capacidades de las autoridades locales y de los organismos internacionales de asistencia y de ayuda humanitaria. Este texto tiene por objeto señalar cómo la crisis sanitaria ha puesto en evidencia algunas dimensiones del conflicto israelo-palestino.

Desde muy pronto el Mediterráneo oriental y Oriente Próximo se vieron tocados por la epidemia; los países más afectados han sido Irán, Turquía, Israel, Egipto y Arabia Saudí, pero todos los países de la región han tenido casos y todos los gobiernos se han movilizados según sus capacidades. A principios de mayo el impacto en Palestina ha sido limitado, 353 casos y 2 muertos, para una población de cerca de 4 millones de habitantes. Israel se ha visto afectada de manera más importante, 16.237 casos y 234 muertos, con 8 millones de habitantes. No vamos a analizar aquí el impacto epidemiológico, su desigual incidencia en ciertos grupos, ni la gestión política de la crisis sanitaria. Nos vamos a detener en su utilización como pretexto para concluir un acuerdo entre las dos principales formaciones políticas, el Likud y el partido Azul y Blanco, tras más de un año de crisis institucional y de tres elecciones legislativas seguidas. Este acuerdo de gobierno de coalición que parecía imposible ha sido presentado como la respuesta a la emergencia nacional de la pandemia, pero conlleva dos elementos ligados al conflicto israelopalestino: el mantenimiento del paradigma excluyente que ha prevalecido desde 1948 y el anuncio de la anexión inminente de ciertas áreas de Cisjordania.

\section{La pandemia en Israel, pretexto para excluir}

El Estado de Israel es cúmulo de anomalías. Desde su concepción original, el sionismo político tuvo por objeto el establecimiento de un Estado propio para la na- 
ción judía y su aceptación y participación en el concierto de las naciones. Sin embargo su origen de carácter colonial dio lugar a un Estado singular, cuya legitimidad siempre fue cuestionada y finalmente rechazado por su entorno. La normalización internacional sería un tema pendiente no resuelto hasta hoy. También en el plano interno tiene lugar una anomalía; Israel se construye como democracia liberal, pero su origen étnico-nacional, sus prácticas de segregación y discriminación, y la conflictividad permanente, han hecho de la supuesta "única democracia de Oriente Medio" un caso de democracia étnica. Un régimen democrático para la población judía pero en menor medida para la población no judía.

Por otra parte, el sistema político israelí lleva las últimas dos décadas conmocionado. Desde principios de los 2000s los grandes partidos tradicionales han perdido peso, la fragmentación del Parlamento es mayor y las coaliciones de gobierno se han hecho muy volátiles. Además han ganado relevancia los partidos políticos árabes/palestinos en la escena parlamentaria, convirtiéndose en la tercera fuerza política. Esto ha agudizado las tensiones entre el espectro sionista y la minoría árabe, y ha reforzado el axioma de la exclusión de los partidos árabes de cualquier acuerdo con legitimidad sionista, poniendo en evidencia los límites del sistema democrático israelí ${ }^{3}$.

Los palestinos con ciudadanía israelí son la principal comunidad no judía de Israel. Son los descendientes de la población árabe autóctona que preexistía antes de la creación del Estado de Israel y que, por diferentes circunstancias, no fueron expulsados en la limpieza étnica de 1948-1949 o que no optaron por refugiarse en las áreas que quedaron bajo control árabe durante la guerra. Según las estadísticas oficiales israelíes, a finales de 2018 la población árabe alcanzaba la cifra de 1.878 .400 personas lo que equivale al 20,9\% de la población (CBS, 2019). Con una necesaria corrección que detraiga los palestinos de Jerusalén Este y a los sirios del Golán ocupado, que sólo son residentes y no ciudadanos, los árabes con ciudadanía israelí suman 1.492.000, y suponen el 17,4\% del total. Es decir, uno de cada 6 ciudadanos israelíes que vive en Israel es palestino, y dado que la media de edad de los árabes es más baja, uno de cada 7 israelíes con derecho a voto es palestino ( $14 \%$ del cuerpo electoral).

Sin embargo debe señalarse que esta minoría siempre ha sido un cuerpo extraño en Israel, porque es una parte de la ciudadanía (de iure) pero ajena al ethos fundacional y que mayoritariamente no se reconoce en el proyecto nacional. Es el remanente de la realidad árabe palestina preexistente y un permanente recordatorio de cómo se estableció el Estado, a través del colonialismo, la limpieza étnica y la desposesión. No sólo eso, para muchos siempre ha sido una extensión del enemigo árabe dentro de casa, una potencial quinta columna. Por ello la población árabe, todavía hoy segregada en más de un centenar de localidades y barrios árabes en una decena de ciudades mixtas, estuvo primero sometida a un régimen de excepción (el llamado "gobierno militar") entre 1949 y 1966, que permitió a las autoridades establecer un sistema de control, mediante la vigilancia, la cooptación y división. En

\footnotetext{
Nos encontramos así con una versión en Oriente Medio de la conventio ad excludendum, fórmula utilizada para denominar un acuerdo explícito o tácito entre algunos partidos políticos, fuerzas sociales y poderes económicos, cuyo propósito es la exclusión de un determinado tercero de ciertas formas de alianza, participación o colaboración. Un ejemplo clásico tuvo lugar en la Italia de posguerra para impedir la llegada del partido comunista al gobierno.
} 
ese período se sientan las bases de una realidad que perdura hasta hoy, un enfoque securitario sobre la minoría y un estatus de grupo subalterno y discriminado, y la creación de una ciudadanía de segunda clase.

La población palestina en Israel es una dimensión singular de la "palestinidad": una población indígena que ha resistido, que todavía es suficientemente numerosa, y que ha mantenido su identidad árabe palestina a pesar del aislamiento de su entorno (Pappe, 2011). En un país que ha hecho gala de haber dado nacimiento a una nueva sociedad judía israelí, crisol de múltiples culturas e identidades diaspóricas, los palestinos son la principal minoría étnica no judía y por lo tanto ajena a ese melting pot. La razón de ello reside en que es la población originaria en un Estado de origen colonial, que ha perpetuado sus prácticas excluyentes y que trata de manera diferenciada a los indígenas, sea dentro de sus fronteras, a modo de colonialismo interno como, a partir de 1967, en los territorios que ocupe.

Como ciudadanos israelíes, estos palestinos siempre han tenido derechos civiles y políticos reconocidos; votan, tienen representación parlamentaria desde 1949, tienen alcaldes, tienen organizaciones políticas y han desplegado una acción colectiva propia y singular, en suma participan de la actividad política del país. Sin embargo al no formar parte de la nación, han sido extraños a la legitimidad sionista y siempre han sido excluidos de cualquier coalición de gobierno. Hasta los años noventa su presencia parlamentaria había sido modesta, generalmente en el marco de un partido refugio (el Partido Comunista israelí, y su heredero, el Frente Democrático por la Paz y la Igualdad HADASH), en los partidos sionistas, y más recientemente en nuevas formaciones políticas árabes. A partir de los noventa, en paralelo al Proceso de paz de Oslo y a su fracaso, el campo político árabe en Israel vivió una singular reconfiguración. En primer lugar cristalizaron tres fuerzas palestinas relevantes que afirmaron su presencia parlamentaria: el HADASH laico y de tradición comunista, el Movimiento Islámico conservador, y Balad, una nueva formación nacionalista palestina y antisionista. El segundo fenómeno fue que el voto árabe en Israel, tradicionalmente disperso, cambió: empezó a haber una fuerte abstención (por rechazo al sistema político) y el voto efectivo se dirigió esencialmente a las listas árabes, lo que se tradujo en un aumento de la presencia de diputados palestinos en la Knesset. A esto se sumó que por primera vez, en marzo de 2015, las tres formaciones decidieron presentarse en una Lista Conjunta obteniendo unos resultados inusitados: un apoyo del $82 \%$ a esta lista y la obtención de 13 escaños, convirtiéndola en la tercera fuerza política del Parlamento. Estos cambios son la incuestionable expresión de un reforzamiento de la identidad política palestina de la minoría, en un contexto de derechización nacionalista en Israel y de deriva iliberal en los últimos 15 años (Ghanem y Khatib, 2017). Aparece así en la escena política israelí un actor inesperado, un bloque parlamentario árabe mucho más visible y beligerante, lo que contribuye a poner la cuestión de la minoría en el debate público. Durante esa legislatura se aprueba la polémica Ley Básica del Estado-nación judío ${ }^{4}$, y la Knesset se convierte en escenario de una confrontación, a veces virulenta, entre la derecha sionista antiárabe y la Lista Conjunta.

$4 \quad$ El 19 de julio de 2018 se aprueba la Ley Básica del Estado-nación del Pueblo judío (Basic Law: Israel. The Nation-State of the Jewish People, Hok HaLeom), de rango constitucional, que por primera vez establece de manera explícita el derecho exclusivo de los judíos a la identidad nacional. En ella se afirma: El derecho a 
La máxima expresión de esta dinámica tiene lugar en el último año. Entre abril de 2019 y marzo de 2020 se celebran tres elecciones legislativas dado los resultados ajustados y la incapacidad de los principales partidos de formar gobierno. En las primeras elecciones, en abril 2019, la Lista Conjunta no se reedita y los resultados serán adversos para los palestinos: baja la participación y sólo obtienen 10 escaños. Sin embargo en las dos siguientes, en septiembre de 2019 y marzo de 2020, se reconstituye la Lista Conjunta y los resultados superan todas las expectativas. En marzo la participación árabe es del $64,7 \%$ (la más alta en veinte años) y la Lista Conjunta capta el 87,2\% del voto en las localidades árabes. Con 15 escaños la Lista Conjunta se afirma como tercera fuerza política de la Knesset y socio imprescindible para conformar un gobierno de coalición de centro izquierda que acabe con cuatro legislaturas conservadoras.

Esta irrupción hace reemerger de manera la cuestión de contar o no con los árabes, y de aceptarles como actores legítimos. Sin embargo a la hora de intentar formar gobierno Gantz, el exmilitar rechazará el apoyo árabe y terminará pactando con su rival. El 20 de abril, contra todo pronóstico, Benjamin Netanyahu y Benny Gantz suscriben un acuerdo de gobierno con el pretexto de la necesidad apremiante de un ejecutivo estable para hacer frente a la pandemia ${ }^{5}$. El acuerdo supone la rotación de los dos dirigentes en el cargo de Primer Ministro, el mantenimiento de la inmunidad gubernamental para Netanyahu cuando sea viceprimer ministro (protegiéndole ante varios procedimientos judiciales en curso), la conformación de una coalición de gobierno y una mayoría parlamentaria en la que suman centristas, conservadores, ultraortodoxos y extrema derecha nacionalista; y finalmente un programa de gobierno común. La pandemia ha servido así de trampantojo para encubrir la razón fundamental del acuerdo, mantener la primacía de un gobierno sionista y sin árabes. Se ha vuelto a repetir el axioma central del sistema político israelí: la exclusión de los partidos árabes del ejecutivo de Israel. Una decisión que revela la incapacidad de los liberales de superar la democracia étnica israelí. Hoy se da la paradoja de que la principal formación política de oposición en la Knesset israelí, no es la izquierda histórica laborista ni siquiera una coalición centrista, sino la Lista árabe Conjunta que representa a la minoría nacional palestina en Israel.

\section{La pandemia en Israel, pretexto para anexar}

El acuerdo de gobierno del 20 de abril conlleva un punto de especial trascendencia respecto al conflicto palestino: la inminente anexión de ciertas áreas ocupadas. Israel ocupa Cisjordania y Gaza desde junio de 1967 en un caso insólito de ocupación beligerante prolongada que ya dura más de cincuenta años, desatendiendo numerosas resoluciones del Consejo de Seguridad de Naciones Unidas que instan a su retirada y con el agravante de que unilateralmente Israel no se siente obligada a

ejercer la autodeterminación nacional en el Estado de Israel es exclusivo del pueblo judío (Art.1c); el he-breo es la lengua oficial. La lengua árabe tendrá un estatuto especial (Art.4).

5 Netanyahu declararía "Le prometí al Estado de Israel un gobierno de emergencia nacional que actuará para salvar las vidas y los medios de subsistencia de los ciudadanos israelíes", y su nuevo socio Gantz: "Hemos evitado una cuarta elección. Protegeremos la democracia. Lucharemos contra el coronavirus y cuidaremos a todos los ciudadanos de Israel” (BBC, 20 de abril 2020). 
cumplir con la Cuarta Convención de Ginebra. Desde 1967 Israel ha desarrollado varias políticas sobre estos territorios: formalmente Israel "administra" estos territorios que no forman parte del territorio del Estado si bien en 1980 anexó la parte oriental de la ciudad de Jerusalén y los Altos del Golán sirio; en agosto de 2005 Israel se retiró de Gaza; y finalmente a raíz de los Acuerdos de Oslo (1993-2000) se retiró de las principales ciudades de Cisjordania, traspasando competencias civiles y de seguridad a las autoridades interinas palestinas. Todo ello no ha cambiado el estatus legal vigente de estos territorios; según el Derecho Internacional, toda Cisjordania y Gaza, incluida la parte oriental de Jerusalén son territorios ocupados hasta el día de hoy. En estas cinco décadas Israel ha propiciado la instalación de población civil en los territorios ocupados; estos colonos han alcanzado la cifra de más de 650.000 . Esta colonización, a todas luces ilegal, ha sido una práctica de hechos consumados que Israel pretende sean irreversibles mediante su aceptación y legalización en un futuro acuerdo político con los palestinos con la bendición internacional.

El colapso del proceso de Oslo a partir del 2001, con la suspensión de las negociaciones parciales y el enconamiento de la confrontación violenta, llevó a Israel a tomar medidas unilaterales de carácter territorial (construcción del muro, intensificación de la colonización y de las infraestructuras, retirada de Gaza y bloqueo) con miras a imponer por la fuerza un reordenamiento del espacio colonizado y progresar en su irreversibilidad. De esta forma Israel, aún siendo un Estado independiente y reconocido por la comunidad internacional, no cesó en sus prácticas de colonialismo de asentamiento (settler colonialism) propios del período anterior a la independencia. Sin embargo nunca ha logrado que la comunidad internacional admitiera esas prácticas ni esos hechos consumados. Hasta la llegada de Donald Trump.

El presidente Trump, rehén de sus apoyos electorales y vínculos con los sectores neoconservadores y más prosionistas estadounidenses, dio una serie de pasos que rompieron con la política tradicional de Washington. Entre 2018 y 2019 trasladó la embajada estadounidense en Israel a Jerusalén, cambió el discurso oficial sobre la ocupación y se ofreció a diseñar y proponer un plan para de resolución definitiva del conflicto. A esto se sumó una retahíla de medidas punitivas para doblegar a los palestinos: suspensión de la ayuda, retirada estadounidense de varios organismos multilaterales, amenazas a organizaciones internacionales por su apoyo a los palestinos, cierre de la oficina de la OLP en Washington. Por primera vez Israel contaba con un apoyo externo explicito a sus planes de legalización de la ocupación. Con tal cobertura, en las campañas electorales de 2019 y 2020 Netanyahu prometió la anexión de los grandes bloques de asentamientos y otros emplazamientos estratégicos en Cisjordania. Tal promesa no sólo iba dirigida a ganarse el voto de los colonos y los sectores nacionalistas, sino que era una oportunidad para aprovechar el respaldo explícito de Trump a planes de ampliación del territorio israelí. Para no quedarse atrás el "centrista" Gantz, también necesitado de votos, nunca tomó una posición firme en contra de la ocupación y las anexiones.

En plena campaña electoral israelí, el 28 de enero de 2020, se dio a conocer el esperado "Acuerdo del siglo" (Deal of the Century) cocinado en Washington y que lleva el pomposo nombre de "Peace to prosperity. A vision to improve the lives of the Palestinian and Israeli people". Formalmente es una propuesta de discusión para palestinos e israelíes, pero en la práctica es un diktat porque ha ido precedido y acompañado de amenazas de represalias en caso de rechazo. Su lógica es que los 
palestinos deben asumir su derrota y aceptar la oferta "realista" que al menos les puede reportar territorio, un mínimo autogobierno y una cierta prosperidad económica. El documento plantea la anexión de una parte de las zonas ocupadas (un 30\% de Cisjordania, incluido el Valle del Jordán) y la creación de una entidad palestina tutelada y con soberanía limitada, a cambio de un supuesto maná financiero que vendría de donantes diversos. Además plantea la posibilidad de intercambiar territorio: Israel cedería zonas con minoría palestina en la región fronteriza del Triángulo a cambio de los asentamientos, y se ampliaría la franja de Gaza con territorio desértico a lo largo de la frontera israelo-egipcia ${ }^{6}$. Obviamente los palestinos rechazaron categóricamente la propuesta estadounidense a la que consideran una provocación inaceptable (State of Palestine, 2020a). Asimismo la mayor parte de los actores internacionales, desde Naciones Unidas hasta la Unión Europea, China y los países árabes, cuestionaron radicalmente la propuesta y advirtieron que no reconocerían las medidas unilaterales y las anexiones.

Si bien el plan de Trump tiene muy pocos visos de ser ni siquiera discutido, Netanyahu recibió con él un espaldarazo político significativo. La propuesta era la luz verde para continuar una nueva fase de hechos consumados. Es así que de nuevo, con el pretexto de la emergencia sanitaria, el acuerdo de gobierno del 20 de abril incluye un paso más en la colonización israelí: a partir del 1 de julio se podrá discutir en el Parlamento y aprobar la anexión de más territorios palestinos. Dado el actual equilibrio de fuerzas no se descarta que Netanyahu logre una mayoría suficiente para ello lo que supondría un enconamiento entre Palestina e Israel de imprevisibles consecuencias.

\section{La pandemia en Palestina, añadida a la ocupación}

Palestina se vio tocada por la pandemia a mediados de marzo. En Cisjordania, los primeros casos se conocieron en Belén a mediados de marzo relacionados con un grupo de turistas ortodoxos. En Gaza, los primeros contagios fueron detectados el 21 de marzo y se atribuyen a unos palestinos procedentes de Pakistán donde habían viajado para atender una formación religiosa. A principios de mayo se contaban 353 casos confirmados por el Ministerio palestino de Sanidad (17 en Gaza y 336 en Cisjordania) y 2 muertos. A estos se sumaban 169 casos en Jerusalén Este ocupada, registrados por las autoridades israelíes.

Estos bajos índices de impacto se pueden deber a varios factores, probablemente haya un infravaloración de los casos, también porque los palestinos están acostumbrados a las emergencias y a operar con escasos recursos, y sobretodo porque tomaron medidas rápidas de contención. Tan pronto como se dieron los primeros casos positivos, las autoridades sanitarias palestinas diseñaron un plan de respuesta (COVID-19 response Plan, 26 de marzo) (State of Palestine, 2020b). En Cisjordania las autoridades a mitad de marzo empezaron las medidas de confinamiento y de restricción de los desplazamientos y se impuso el estado de emergencia el 22. En

$6 \quad$ El Triángulo es una región colindante a Cisjordania habitada por más de 300.000 palestinos israelíes. Es una zona con fuerte implantación del islam político y alta concentración del voto en las listas árabes. Con un intercambio de este tipo Israel se desharía de una quinta parte de su minoría árabe y de 3 o 4 escaños árabes en el Parlamento. 
Gaza las autoridades sanitarias del gobierno local y la UNRWA tomaron medidas equivalentes, convirtiendo varias escuelas en centros de confinamiento para varios miles de personas que acababan de ingresar desde Israel o desde Egipto. Asimismo se dejó de repartir ayuda humanitaria en los centros de la UNRWA y se puso en marcha un mecanismo de entrega a domicilio. En ambos casos hubo una respuesta muy temprana de las autoridades, pero también se hizo patente la extrema limitación de recursos de todo tipo (instalaciones, camas, equipos, tests, medidas de protección). Asimismo los principales donantes, coordinados por Naciones Unidas a través de su Oficina de Ayuda Humanitaria (OCHA) diseñaron una acción coordinada, la "Inter-Agency Response Plan for COVID-19" (OCHA-oPT, 2020) para apoyar los esfuerzos locales. El 9 de abril la Unión Europea, principal donante de la Autoridad Palestina, comprometió 71 millones de euros para hacer frente a la crisis sanitaria y garantizar ayuda humanitaria. Qatar ha prometido 150 millones de dólares para las actividades de Naciones Unidas en Gaza. Sin embargo la ejecución de esta asistencia no es fácil ni evidente.

Pero, ¿qué tiene de singular Palestina al abordar esta crisis? Si en cualquier otro escenario la pandemia ha puesto en evidencia los déficits y las fragilidades de los sistemas de prevención, y su especial incidencia en grupos vulnerables, en Palestina esto se suma y se inserta en una situación de anomalía estructural preexistente:

1. En cualquier otro país la respuesta a la amenaza epidemiológica ha venido del Estado, cuyo primer deber es proteger a su ciudadanía. Sin embargo Palestina no tiene un Estado convencional que pueda responder a la crisis. El Estado de Palestina es un caso paradigmático de "casi-Estado", con algunos atributos estatales pero sin soberanía efectiva y con una capacidad de actuación muy limitada. Palestina puede parecer un Estado más: tiene instituciones, tiene un ministerio de Sanidad, mantiene relaciones con otros actores estatales y organizaciones internacionales. Pero no tiene control efectivo del territorio y de las fronteras, no controla los resortes económicos y los ingresos fiscales son muy limitados, depende de un flujo extraordinario de ayuda externa continua para sobrevivir. El funcionamiento de los ministerios, el salario de los funcionarios, la mayor parte de las políticas públicas funcionan gracias a la ayuda internacional.

El cuasi Estado de Palestina tiene el reconocimiento de 136 países, sin embargo se da la paradoja de que los principales donantes europeos, que no cesan de reiterar su apoyo a una solución política del conflicto mediante la "Dos Estados", no reconocen todavía al Estado palestino y supeditan ese paso a un consenso en Bruselas. En la práctica, lo supeditan al visto bueno de Israel. Desde 1994 la comunidad internacional ha venido financiando la preparación y puesta en marcha (state building) de un Estado palestino sin que se haya alcanzado previamente un acuerdo de paz, en una sorprendente inversión de los términos de cualquier resolución de un conflicto. Su falta de decisión política contribuye hoy al status quo.

Además existe otro condicionante de orden político y territorial: el Estado de Palestina está conformado por dos territorios separados y desconectados, Cisjordania y la Franja de Gaza, además de la parte este de Jerusalén, anexada por Israel, donde no puede operar. En estos dos enclaves no operan las mismas autoridades políticas. Desde 2007 una disputa política intrapalestina ha provocado que de hecho existan dos autoridades. La de Gaza ligada al movimiento islamista Hamas y sometida a sanciones internacionales y al bloqueo israelí. La de Cisjordania, ligada 
a la OLP y que recibe el apoyo financiero y político de la comunidad internacional. A esta situación se añade un problema de legitimidad democrática; la división ha pospuesto las elecciones presidenciales y legislativas desde hace cerca de una década y una parte considerable de la población cuestiona no sólo el funcionamiento de los dos gobiernos sino incluso su propia existencia como Estado limitado y dependiente.

A pesar de ello, los dos gobiernos palestinos han movilizado sus limitados recursos para hacer frente a la pandemia. En primer lugar tomando medidas sanitarias y movilizando los medios públicos y privados existentes. Más aún las autoridades han llegado a un acuerdo tripartito con los agentes sociales para amortiguar los efectos de la crisis, evitar despidos masivos y garantizar medidas de salud laboral. Pero el casi-Estado no tiene recursos ni capacidad para dar una respuesta suficiente, ni sanitaria y mucho menos económica: las únicas ayudas y medidas de protección de grupos vulnerables son las que pueden contar con apoyo de los organismos humanitarios. De haber tenido un Estado palestino soberano y rodado, el nivel de dependencia y de incertidumbre sería otro.

2. La pandemia amenaza una realidad muy particular, una situación de ocupación beligerante y de colonización. La creación de una Autoridad Nacional Palestina interina en 1994, transformada en Estado de Palestina en 2010, con ciertas competencias de autogobierno, no ha alterado la realidad global. Cisjordania y Gaza siguen siendo territorios ocupados. Una ocupación desde fuera en el caso de Gaza; mientras que en Cisjordania se mantiene mediante un entramado de colonias, muros de separación y el control fronterizo externo. Para Naciones Unidas y la Comunidad Internacional en su casi totalidad (la excepción es la administración Trump), Cisjordania y Gaza siguen ocupadas, y de acuerdo al Derecho Internacional Humanitario (Convenciones de Ginebra) Israel tiene obligaciones como fuerza ocupante.

En una pirueta digna de caso de estudio en los manuales de derecho internacional humanitario, el tan aplaudido Proceso de paz de 1993 supuso desresponsabilizar a la potencia ocupante de sus obligaciones con la población civil. Dado que se iba a crear un Estado palestino, todas las competencias civiles pasaron a la administración palestina, sin ser esta un Estado, ni tener los medios para actuar como tal. Desde entonces Israel sigue ocupando pero ya no tiene competencias en salud.

Durante estas semanas de crisis, en marzo y abril, la ocupación no se ha visto alterada y las medidas y prácticas habituales de militares israelíes y colonos no se han detenido: los ataques de colonos a campesinos, las detenciones o la destrucción de construcciones palestinas consideradas ilegales por el ocupante. Más aún, afectando directamente las medidas que los palestinos han tomado para hacer frente a la pandemia. El 26 de marzo instalaciones sanitarias de emergencia improvisadas en la comunidad de Ibziq, en el Valle del Jordán, fueron desmanteladas. El 14 de abril el ejército israelí clausuró una clínica en el barrio de Silwan y detuvo a los voluntarios sanitarios porque usaban material provisto por el Ministerio palestino de Salud; Israel prohíbe cualquier actividad de las autoridades palestinas en la ciudad anexionada de Jerusalén. Y la lista de ejemplos puede alargarse.

3. Los refugiados palestinos (más de cinco millones y medio en 2020, dispersos por varios países de Oriente Próximo) constituyen el principal grupo de refugiados de larga duración a nivel mundial. La agencia de Naciones Unidas que les atiende 
desde 1950, la UNRWA, trabaja denodadamente por cubrir sus necesidades básicas con contribuciones voluntarias de los Estados donantes. Pero la Agencia no es solo un mecanismo de ayuda, es también una muestra del compromiso de la comunidad internacional con la defensa del derecho al retorno de los refugiados, tal como establece la Resolución 194 (1948) de la Asamblea General de Naciones Unidas. El papel de la UNRWA es especialmente importante para los refugiados en situaciones más complejas, en Siria, Líbano y Gaza. Después de haber sido uno de los principales donantes durante décadas, en agosto de 2018, el presidente Trump decidió suspender el aporte estadounidense de 360 millones de dólares a la agencia para forzar a los palestinos a aceptar su plan de paz. La medida de Washington provocó una verdadera sangría financiera en la organización. A esto se añade ahora la pandemia. Con una pequeña dotación presupuestaria la UNRWA ha tomado una serie de medidas preventivas de contención en los escenarios más críticos pero que son a todas luces insuficientes y que no podrían dar una respuesta adecuada en caso de extensión. Aquí de nuevo se pone en evidencia la urgente necesidad de garantizar los derechos de los refugiados.

4. El caso de la Franja de Gaza es especialmente grave. Gaza tiene unos dos millones de habitantes, de los cuales 1,4 son refugiados, en un territorio exiguo y sin recursos. En 2012 un informe de Naciones Unidas ya alertó que la Franja sería un lugar invivible/inhabitable en 2020. Desde hace más de diez años los indicadores sociales y económicos son catastróficos: desempleo masivo, deterioro de las condiciones sanitarias, extrema dependencia externa, economía en caída libre. A ello han contribuido el bloqueo que sufre desde 2007 por parte de Israel y Egipto, y las sanciones por parte de la comunidad internacional (restricciones de la ayuda). Literalmente aislada del exterior desde hace 13 años, sin puerto accesible ni aeropuerto, Gaza es una gran cárcel al aire libre.

Gaza tiene una de las tasas de densidad de población más altas del mundo y el hacinamiento es la norma, especialmente después de las ofensivas militares israelíes (2008-9, 2012 y 2014) que han destruido barrios enteros y desplazado decenas de miles de personas. Hoy la media es de 6 personas por unidad familiar y en muchos casos alcanza los 20 residentes en una misma vivienda. A esto se añade que gran parte de la población sobrevive combinando actividades informales, empleos ocasionales, ayudas y solidaridad familiar. En tales condiciones cualquier estrategia de prevención basada en el mantenimiento de distancia interpersonal se hace en extremo difícil.

La situación sanitaria de la Franja es especialmente problemática. Desde hace años las limitaciones de las políticas pública de salud, la insuficiencia de la ayuda externa y el deterioro de las condiciones de vida han configurado un sistema de salud con una capacidad limitada, infradotado y con escasas posibilidades de respuesta al estar sometido el territorio a un bloqueo estricto. En Palestina se dan altas tasas de ciertas enfermedades (en particular diabetes) y en particular en la Franja existen grupos de población especialmente vulnerables por desnutrición y problemas de acceso a agua potable. Al inicio de la crisis de la COVID-19 había 78 camas de UCI y 63 respiradores para dos millones de habitantes. En un reciente texto publicado en The Lancet sobre la violencia estructural que se vive en Gaza en materia de salud, los autores concluían: 
(...) la comunidad internacional debe actuar de inmediato para poner fin a la violencia estructural y confrontar las fuerzas que historica y políticamente han afianzado la violencia y una realidad incierta para los palestinos. Una pandemia de COVID-19 que paralice el sistema sanitario de la Franja de Gaza no debe verse como un inevitable fenómeno biomédico, equivalente al que pueda experimentar la población del resto del mundo, sino como una injusticia biosocial provocada por décadas de opresión israelí y de complicidad internacional prevenible si se hubieran garantizado los derechos sanitarios fundamentales y la autodeterminación de todos los palestinos. (Mills et al., 2020).

5. Finalmente hay también una dimensión propagandística. La impunidad de la que beneficia Israel para mantener este orden y profundizar la colonización ha sido en gran medida producto de una exitosa capacidad de normalizar su relato y hacer admisibles sus argumentos. Pero en los últimos años Israel vive muy malos momentos desde el punto de vista de su imagen y la propaganda hacia el exterior se ha convertido en una cuestión estratégica, haciendo recurso a sus instrumentos diplomáticos y a diversos grupos de apoyo en el exterior, coordinados por el Ministerio de Asuntos estratégicos. La pandemia ha sido aprovechada como una nueva ocasión para que Israel despliegue sus instrumentos de propaganda. Y lo ha hecho con cierto éxito. La prensa internacional y algunos organismos internacionales han felicitado a Israel por su "colaboración" consistente en que el organismo administrador de la ocupación, el COGAT (Israeli Coordination of Government Activities in the Territories) permitiera que la ayuda internacional transfiriera unos miles de tests y mascarillas de la OMS al ministerio de salud palestino. Otra medida aplaudida fue el permiso israelí a que una parte de los 60.000 trabajadores palestinos en Israel pudieran permanecer en Israel para evitar movimientos de población. Lo que no se dice es que los trabajadores con síntomas son expulsados sin contemplaciones a Cisjordania, sin ni siquiera informar a las autoridades, en vez de ser tratados in situ. Claramente esta propaganda tiene por objeto encubrir la realidad de que la ocupación persiste y que las fronteras siguen bajo control total de Israel, cualquier importación se tiene que hacer con el visto bueno del ocupante y en el caso de los productos sanitarios y médicos, a través de empresas importadoras israelíes.

\section{Reflexiones finales}

En esta situación de incertidumbre numerosas voces se han alzado exigiendo a Israel que cumpla con sus obligaciones de protección a la población palestina, permita la entrada de recursos sanitarios y garantice la protección sanitaria a los más de 5000 prisioneros políticos palestinos que se encuentran en cárceles israelíes. En marzo, Michael Lynk, Relator Especial de las Naciones Unidas sobre la situación de los derechos humanos en los territorios palestinos ocupados desde 1967, señalaba "Israel tiene la «obligación legal» de garantizar que los palestinos del Territorio Palestino Ocupado reciban los servicios sanitarios básicos" (UNOHCHR, 2020).

La vulnerabilidad es una condición producida histórica y socialmente, y tiene causas y responsables. Los palestinos no son solamente un grupo vulnerable, sino que están ocupados y desprovistos de sus derechos fundamentales. La vulnerabili- 
dad de la población palestina, en particular de los refugiados y de los pobladores de Gaza, tiene dos responsables: la ocupación israelí que prolonga ad infinitum el proyecto colonial, y la comunidad internacional que a pesar de la retórica ha consentido la perpetuación de esta situación. En cuanto a la pandemia esto provoca que en Palestina la ocupación sea claramente un elemento de comorbilidad de carácter político porque a la crisis sanitaria global, se añade la vulnerabilidad estructural y cronificada producida por la ocupación.

La pandemia subraya y pone en evidencia diferentes dimensiones del conflicto israelo-palestino. Cuando se haya superado la crisis, los palestinos seguirán en su confinamiento habitual hasta que acabe la ocupación. Peor aún, tendrán problemas añadidos porque deberán encarar posibles anexiones, una previsible caída de la ayuda internacional y un probable reajuste en el interés y en las capacidades de actuación en Oriente Medio de los actores externos, como la Unión Europea, que habían desempeñado un cierto papel y contrapeso. En estos días muchos elucubran sobre la nueva escena mundial postcrisis y esperan que se alumbren cambios políticos, económicos, sociales y culturales, de mayor o menor calado. Los palestinos en cambio sólo auguran un agravamiento de la ocupación y del exclusivismo étnico, lo que hace aún más acuciante la necesidad de acabar con este conflicto.

\section{Referencias}

BBC. (2020). Israel's Netanyahu and Gantz sign unity government deal. $B B C, 20$ abril 2020. Recuperado de https://www.bbc.com/news/world-middle-east-52358479

CBS. (2019). Statistical Abstract of Israel 2019. Jerusalem : Central Bureau of Statistics..

Ghanem, A., y Khatib, I. (2017). The nationalisation of the Israeli ethnocratic regime and the Palestinian minority's shrinking citizenship. Citizenship Studies, 21(8), 889-902.

Mills, D., Wispelwey, B., Muhareb, R., y Gilbert, M. (2020). Structural violence in the era of a new pandemic: the case of the Gaza Strip. The Lancet, 26 de marzo. DOI: 10.1016/S0140-6736(20)30730-3

OCHA-oPT. (2020). Covid-19 plan for Palestine. OCHA-oPT, 25 de abril. Recuperado de https://www.ochaopt.org/content/covid-19-response-plan

OCHA. (2020). Coronavirus disease 2019 (Covid-19) Update 23: occupied Palestinian territory, 19 April 2020 (epidemiological week 8). Reliefweb Occupied Palestinian Territory (oPt), 19 de abril. Recuperado de https://reliefweb.int/report/occupiedpalestinian-territory/coronavirus-disease-2019-covid-19-update-23-occupied

Pappe, I. (2011). The forgotten Palestinians. A history of the Palestinians in Israel. New Haven: Yale University Press.

State of Palestine (2020a). State of emergency. Palestine's Covid-19 Response Plan. Ramallah Recuperado de www.corona.ps

State of Palestine (2020b). Exposed: The "Con of the Century" will not bring peace. Ramallah: Palestinian Liberation Organization - Negotiations Affairs Department, FAQs February 09, 2020.

United Nations - OHCHR (2020). Covid-19: Israel tiene la obligación legal (...). OHCHR, 19 de marzo. Recuperado de https://www.ohchr.org/SP/NewsEvents/Pages/DisplayNews.aspx?NewsID=25728\&Lan $\mathrm{gID}=\mathrm{S}$ 